

\title{
Gênero nas Políticas Educacionais do Estado da Paraílba: (Des)Continuidades
}

\author{
Género en las Políticas Educacionales del Estado de Paraíba: \\ (Dis)Continuidades
}

\section{Gender in the Educational Policies of the State of Paraiba: (Dis)Continuities}

\section{Resumo}

O presente artigo objetiva discutir a generificação ${ }^{1}$ das políticas educacionais e curriculares para a Educação de Jovens e Adultos na rede estadual de ensino do estado da Paraíba, após os avanços do conservadorismo no cenário nacional e internacional. Foram analisadas a Lei $\mathrm{N}^{\mathrm{o}}$ 10.488, de 23 de junho de 2015 e as Diretrizes Operacionais para o Funcionamento das Escolas da Rede Estadual de Ensino de 2012 a 2017. Elegemos como aportes teóricos autores/as como Silva (1994); Gentili (1995); Cadernos de Pesquisa (1997); Peroni (2003); Oliveira (2000); Freitas (2012); Bowe, Ball e Gold (1992) e Ball (1989, 1994); Ball, Maguire e Braun (2016). Os estudos e pesquisas destes últimos autores/as fazem parte do nosso microscópio epistemológico por realizarem análises sobre as políticas educacionais que provocaram as reformas educacionais na Inglaterra e se desdobraram no cenário mundial. Argumentamos que essa perspectiva de análise das políticas educacionais direciona nossa compreensão em tempos políticos marcados pela expansão do conservadorismo e fundamentalismo. Assim, negligenciar as questões inerentes à diversidade fortalece a sua invisibilidade nos espaços formativos dos profissionais da educação, alargando-se um espaço de fomento do pensamento conservador.

Palavras-Chave: Políticas; Educação; Currículo; Gênero.

\section{Resumen}

El presente artículo tiene como objetivo discutir la generificación ${ }^{1}$ de las políticas educativas y curriculares para la Educación de Jóvenes y Adultos en la red estatal de enseñanza del estado de Paraíba tras los avances del conservadurismo en el escenario nacional e internacional. Se analizaron la Ley $\mathrm{N}^{\mathrm{o}} 10.488$, de 23 de junio de 2015 y las Directrices Operativas para el Funcionamiento de las Escuelas de la Red Estatal de Enseñanza de 2012 a 2017. Elegimos como aportes teóricos autores/as como Silva (1994); Gentili (1995); Cadernos de Pesquisa (1997); Peroni (2003); Oliveira (2000); Freitas (2012); Bowe, Ball e Gold (1992) e Ball (1989, 1994); Ball, Maguire e Braun (2016). Los estudios e investigaciones de estos últimos autores/as forman parte de nuestro microscopio epistemológico por realizar análisis sobre las políticas educativas que provocaron las reformas educativas en Inglaterra y se extendieron en el escenario mundial. Argumentamos que esa perspectiva de análisis de las políticas educativas dirige nuestra comprensión en tiempos políticos marcados por la expansión del conservadurismo y el fundamentalismo. Así, descuidar las cuestiones inherentes a la diversidad, fortalece su invisibilidad en los espacios formativos de los profesionales de la educación, ampliando un espacio de fomento del pensamiento conservador.

Palabras-Clave: Políticas; Educación; Currículo; Género.

Rafael Ferreira de Souza Honorato, Maria Zuleide da Costa Pereira 


\section{Abstract}

This article aims to discuss the genderification ${ }^{1}$ of educational and curricular policies for Youth and Adult Education in the state education network of the state of Paraíba after the advances of conservatism in the national and international scenario. We analyzed Law No. 10,488, dated June 23, 2015 and the Operational Guidelines for the Operation of Schools of the State Education Network from 2012 to 2017. For the development of the study we chose as theoretical contributions authors such as Silva (1994); Gentili (1995); Research Papers (1997); Peroni (2003); Oliveira (2000); Freitas (2012); Bowe, Ball and Gold (1992); Ball $(1989,1994)$ and Ball, Maguire e Braun (2016). The studies and researches of these last authors are part of our epistemological microscope for carrying out analyzes on the educational policies that provoked the educational reforms in England and unfolded in the world scene. We argue that this perspective of educational policy analysis directs our understanding in political times marked by the expansion of conservatism and fundamentalism. Thus, neglecting the issues inherent in diversity strengthens its invisibility in the educational spaces of education professionals, widening a space for the promotion of conservative thinking.

Keywords: Policies; Education; Curriculum; Gender.

\section{Introdução}

Estudos como os de Silva (1994), Gentili (1995), Cadernos de Pesquisa (1997), Peroni (2003) e Oliveira (2000) ressaltam que as mudanças no cenário das políticas educacionais brasileiras, advindas das reformas neoliberais, afetaram as políticas públicas que contemplavam os mais pobres, em mais um momento de refração do mercado de trabalho e da desvalorização da renda das famílias brasileiras. Com isso, inúmeros países, entre eles o Brasil, apresentam um quadro repleto de contradições. De um lado, ressalta-se a conquista de direitos sociais resultantes da promulgação da Constituição Federal de 1988. De outro, ocorria a reorientação das políticas que levaram à restrição de espaços públicos e democráticos, reduzindo as questões políticas a problemas técnicos, sob o argumento de má gestão, desperdício, falta de formação e inadequação de currículos.

Para Sader (2013), com os governos de Lula (2003-2010) e Dilma (20112016) o Brasil viveu tempos de pós-neoliberalismo, devido à prioridade que esses governos deram às políticas sociais e à reinserção internacional do Brasil. Tal perspectiva rompeu com a ideia de Estado mínimo que seguia a doutrina liberal de mercado com a inserção de políticas favoráveis ao capital financeiro. Pelo contrário, espaços de discussão democrática foram criados e fortalecidos, pautas das classes populares foram discutidas e ouvidas, iniciouse um processo para pensar e exercitar uma sociedade democrática, solidária e humanista.

Entretanto, Costa (2016) diz que assistimos assustados ao desmonte do Estado democrático de direito com o impeachment da Presidenta Dilma. O que temos é uma caminhada para um processo de privatizações do patrimônio público, desvinculando do Estado a responsabilidade com as demandas das

1 Termo utilizado por Connell e Pearse (2015).

Rafael Ferreira de Souza Honorato, Maria Zuleide da Costa Pereira 
classes populares, com a justificativa de restrição dos gastos públicos. Esse desmonte traz consigo um prejuízo para as políticas públicas de equidade em todos os sentidos. Como diria Apple (2002, p. 109), estamos vivendo um momento de "guinada para a direita". $\mathrm{Na}$ visão do autor essa "guinada" reverbera diretamente na educação e no que seria "conhecimento legítimo", "Sociedade" e "Justiça". Destacando estudos como os de Rury e Mirel (1997), Teitelbaum (1996), Selden (1999), compreende-se que tais conflitos possuem raízes profundas atingindo questões como raça/etnia, gênero, classe social, etc.

Nesse momento, lembramo-nos da célebre frase de Simone de Beauvoir: 'Nunca se esqueça de que basta uma crise política, econômica ou religiosa para que os direitos das mulheres sejam questionados. Esses direitos não são permanentes. Você terá que se manter vigilante durante toda a sua vida'. Em tempos de conservadorismo, o gênero que é um "elemento constitutivo de relações sociais fundadas sobre as diferenças percebidas entre os sexos (e como) um primeiro modo de dar significado às relações de poder" (SCOTT, 1995 , p. 14) bem como é uma dimensão “[...] central da vida pessoal, das relações sociais e da cultura é uma arena em que enfrentamos questões práticas difíceis no que compete à justiça, à identidade e até à sobrevivência" (CONNEL; PEARSE, 2015, p. 25).

Em análise feita na Inglaterra, Ball (1994) destaca que a:

[...] restauração cultural neoconservadora liga a educação, a família e o passado. A linguagem nacional e a identidade nacional desempenham um papel chave nisso (BALL et al., 1990). [...] Através de lutas para controlar a forma da linguagem e estabelecer limites firmes em torno da definição do cânone literário, marcadores de identidade nacional e étnica e uma base para a regulação moral e social são estabelecidos. "Pois a linguagem está na raiz da identidade humana, e manipular isso é poesia ou traição" (EAGLETON, 1993, p. 35). [...] A diversidade étnica e cultural é tornada invisível pela recomposição da língua inglesa no currículo nacional. Um passado imaginário de glórias nacionais e influência civilizadora deve servir de modelo e de guardião para o futuro. "Os neoconservadores veem o seu papel, por um lado, na mobilização de passados que podem ser aceitos com aprovação e, por outro, na neutralização desses passados que só provocariam críticas e rejeições" (HABERMAS, 1985, p. 91). A cultura é transformada em artefato, a história se torna um "museu da informação" (ARONOWITZ; GIROUX, 1991). "Estamos lidando aqui com ideólogos para quem a linguagem é assentimentalmente um caso elocucionário, a poesia é uma espécie de patriotismo métrico, uma literatura inglesa é uma Stonehenge semântica" (EAGLETON, 1993, p. 35). Em Bernstein, o Curriculum Nacional estabelece um conjunto de "isolamentos" [...] (BALL, 1994, p. 5, tradução nossa).

Tendo em vista todos os aspectos destacados até aqui, e considerando questões importantes ressaltadas por Apple (2002) ao afirmar que estamos 
vivendo momentos onde outro bloco de poder assume uma grande influência na educação e nas políticas sociais, em razão desse significativo alerta, neste texto nos propomos a analisar as questões de gênero das políticas educacionais e curriculares voltadas para a Educação de Jovens e Adultos (EJA), na rede estadual de ensino do estado da Paraíba, numa conjuntura política nacional desfavorável tanto de ampliação como de fortalecimento em consequência do avanço do conservadorismo.

Metodologicamente, como estratégia de investigação, realizamos uma pesquisa documental e bibliográfica, por entendermos que elas se complementam. Buscamos analisar a Lei No 10.488, de 23 de junho de 2015, que institui o Plano Estadual e Educação da Paraíba (PEE) com vigência de 2015 a 2025 e as Diretrizes Operacionais para o Funcionamento das Escolas da Rede Estadual de Ensino de 2012 a 2017, documentos produzidos pela Secretaria de Estado da Educação, bem como recorremos a autores como Ball (1989, 1994); Ball, Maguire e Braun (2016); Bowe, Ball e Gold (1992), que realizaram estudos e pesquisas nas reformas educacionais da Inglaterra.

\section{Microscópio Epistemológico}

Assim como Bowe, Ball e Gold (1992, p. 19, tradução nossa) nossas análises pretendem "[...] afastar-se analiticamente de um modelo de controle do Estado, embora ainda reconhecendo que o Estado, as LEAs e as escolas são diferencialmente capacitados, ao longo do tempo, dentro do processo político". Para isso, o trabalho de pesquisa que vimos realizando junto ao Grupo de Estudos e Pesquisas em Políticas Curriculares (GEPPC) com os/as outros/as pesquisadores/as, segue os matizes conceituais pós-estruturais baseados no trabalho de Bowe, Ball e Gold (1992); Ball (1989, 1994); Avelar (2015) e Ball, Maguire e Braun (2016).

Tal posicionamento quanto à descentralização do Estado está respaldado no uso que o autor faz das teorias de Foucault (1981, p. 94, tradução nossa) quanto ao local do Poder. De acordo com o citado autor, "[...] as relações de poder não estão em posições superestruturais, com um mero papel de proibição ou acompanhamento, um papel diretamente produtivo, onde quer que estejam em jogo [...]". Assim, Ball (1994, p. 20, tradução nossa) compreende que o poder produz textos políticos com aspecto "[...] múltiplo, sobreposto, interativo e complexo, os textos de política entram e não simplesmente mudam as relações de poder: daí, a complexidade da relação entre as políticas, textos, interpretações e reações [...]".

Fizemos opção pela abordagem do Ciclo Contínuo de Políticas porque “[...] tentamos chamar a atenção para o trabalho de recontextualização de políticas que ocorre nas escolas [...]" (BOWE; BALL; GOLD, 1992, p. 19, tradução nossa). Além de destacar a natureza complexa e controversa das políticas educacionais, essa perspectiva epistemológica leva em consideração as ações dos profissionais da educação que "atuam" nas políticas, colocando-as em ação, no contexto da prática indicando a necessidade de se articular os processos macro, meso e micro nas análises das políticas educacionais.

Bowe, Ball e Gold (1992, p. 19, tradução nossa) pressupõem três contextos principais: influência, produção do texto e prática. Ball (1994) somou a esses 
três contextos os resultados/efeitos e a estratégia política. Tais contextos são inter-relacionados, não possuem uma dimensão temporal ou espacial e não são lineares. Ball, durante entrevista a Avelar (2016), relaciona a ideia do ciclo a um "aninhado", onde podemos focar nossas análises num contexto, mas não há como separá-los. Cada um dos contextos apresenta suas arenas, lugares e interesses de grupos sociais.

Nessa escolha, leve-se em consideração a trajetória da política através das teorizações dos supracitados autores; também nos aproximaremos das concepções destes no que tange ao conceito de política. Para Ball (1994) não é algo simples de delinear pela multiplicidade de sentidos que pode assumir; então, o autor opta por entender a política como texto e discurso. Todavia, apesar da separação ele chama a nossa atenção para o fato de que "[...] essa política não é uma ou outra, mas ambas: elas estão 'implícitas' uma na outra. [...] Não [devemos] nos induzir em suposições não examinadas sobre as políticas como 'coisas'; Políticas também são processos e resultados [...]" (BALL, 1994, p. 15, tradução nossa).

Olhar para as políticas, através deste microscópio epistemológico, evitará as superficialidades e incoerências em nossas análises, tendo em vista que:

[...] parece-nos que a imagem implícita na concepção de conjuntos distintos e desconectados de formuladores de políticas e implementadores de políticas serve de fato ao poderoso propósito ideológico de reforçar uma concepção linear de política em que a teoria e a prática são separadas e a primeira é privilegiada [...] (BOWE; BALL; GOLD, 1992, p. 10, tradução nossa).

Para nos distanciarmos dessa concepção linear da política, é necessário 'apagar" a palavra "implementação" das pesquisas em políticas educacionais. Pois, para Bowe, Ball e Gold (1992), esta é uma estratégia que, através do campo linguístico, reforça que as políticas são filtradas para baixo pelos organismos de Estado, ignorando os antagonismos existentes na política e reforçando a racionalidade do processo de gestão da política.

Então, substituiremos a palavra "implementação" pelo termo "atuação" apresentado por Ball, durante entrevista com Avelar (2016, p. 6). Para o autor, a atuação é um processo criativo; o resultado do processo criativo é algo diferente daquilo que estava escrito no texto. Todavia, reconhecendo que "[...] a atuação é em parte produzida discursivamente, que as possibilidades de se pensar e falar sobre políticas são, na verdade, articuladas dentro de limites de certas possibilidades discursivas [...]" (AVELAR, 2016, p. 6), assim, a atuação é um processo "[...] local, contingencial e algumas vezes frágil [...]" (AVELAR, 2016, p. 6).

Ao pensar nas possibilidades discursivas Bowe, Ball e Gold (1992) recorrem a Hawkes (1977) e ao conceito de texto "readerly" e "writerly". Trabalharemos esses dois conceitos em nossas análises documentais. Sobre o que eles tratam? O primeiro se refere a textos das políticas e à relação entre

2 Expressão usada por Ball em entrevista concedida a Avelar (2015). Disponível em: $<$ http://epaa.asu.edu/ojs/ article/download/2368/1743>. Acesso em 1 janeiro de 2017.

Rafael Ferreira de Souza Honorato, Maria Zuleide da Costa Pereira 
significante e significado; nesse caso há o mínimo de possibilidade para a interpretação criativa do leitor. Um belo exemplo seria uma leitura da nossa Base Nacional Comum Curricular (BNCC), onde os componentes curriculares, os conteúdos e os objetivos para cada conteúdo a serem alcançados em seus respectivos anos de ensino sugerem o que os autores chamam de "readerliness", ou seja, impossibilidade de subversão pelos atores políticos da escola dando maior espaço à fidelidade ao prescrito no texto.

O segundo conceito, por sua vez, daria maiores possibilidades de interpretação levando o leitor a contribuir com a gestão da política. Mas esse jogo é aberto e exige um grau de interpretação e criticidade, senão pode gerar uma falsa sensação de propriedade. Elencamos a nossa BNCC mais uma vez como exemplo, que, como bem falou Rocha (2016), tratou-se de um processo de legitimação de algo que já estava pronto. Todavia, os atores da escola irão produzir novas políticas para atender às especificidades da BNCC. Referimonos à revisão dos Projetos Político-Pedagógicos (PPP), planos de ensino, regimentos, etc., o que nos faz compreender que um único texto pode contemplar essas dimensões.

Logo, é fundamental que reconheçamos que esses dois tipos de texto, "readerly" e "writerly", fazem parte da gestação de qualquer política. Bowe, Ball e Gold (1992) destacam que:

[...] esses textos 'readerly' e 'writerly' são os produtos de um processo político, processo que já indicamos, emerge de uma interação contínua com uma variedade de contextos inter-relacionados. Consequentemente, os textos têm relação clara com os contextos particulares em que são usados [...] (BOWE; BALL; GOLD, 1992, p. 12, tradução nossa).

Entretanto, compreendemos que mesmo o processo político sendo aberto à (re)contextualização é difícil controlar ou prever os efeitos da política. Logo:

[...] diferentes consequências materiais derivam de interpretações diferentes em ação. Os praticantes serão influenciados pelo contexto discursivo dentro do qual surgem as políticas. Alguns olharão para vantagens pessoais, locais, materiais ou de outro teor, as quais podem decorrer de leituras particulares de textos da política [...] (BOWE; BALL; GOLD, 1992, p. 23, tradução nossa).

Assim, a política carrega consigo (im)possibilidades quando pensada dentro de contextos específicos. Concordamos com Bowe, Ball e Gold (1992) quando defendem o grau de reconhecimento de determinada política diferente, o que pode gerar novas possibilidades dentro de um diálogo político macro, meso e micropolítico, tendo como resultado contradições, refutamentos e novas práticas na medida em que uma boa leitura do texto gere diferentes consequências e implicações para a prática.

Partindo desses pressupostos, percebemos o currículo como uma rede de significações que, ao longo do trajeto, leva em consideração tempo e espaço, e

Rafael Ferreira de Souza Honorato, Maria Zuleide da Costa Pereira 
em cada um deles produz novos sentidos e demandas sociais. Isto quer dizer que o deslocamento de um currículo nacional, centrado nos modelos da cultura dominante, pode se transformar em um currículo mais plural que contemple as culturas, os direitos humanos, éticos, emancipacionistas, inter e transdisciplinares, etc. (PEREIRA, 2009).

\section{O Contexto: Trajetória e Impactos}

O momento conjuntural que o Brasil vive ao mesmo tempo em que escrevemos este texto é um movimento de ruptura democrática. O impeachment da Presidenta Dilma e o avanço do conservadorismo no cenário da política nacional representa um risco sem precedentes aos diretivos sociais, à educação e à cidadania. Trata-se de um momento onde se busca romper com as políticas públicas educacionais que enfrentam as desigualdades e buscam universalizar o acesso a uma educação de qualidade social.

Referente aos avanços sociais conquistados pelo governo da Presidenta Dilma, Chaui (2016, p. 15) destaca que "estudos, pesquisas e análises mostram que houve uma mudança profunda na composição da sociedade brasileira, graças aos programas governamentais de transferência de renda, inclusão social e erradicação da pobreza". Sobretudo, houve um avanço no que concerne aos direitos sociais das classes populares, referente às mulheres e jovens. A autora destaca que foram mudanças operadas no plano da cultura e dos valores simbólicos.

Em contrapartida a um governo que vinha juntamente com a Constituição de 1988 buscando os avanços em termos de igualdade - governo Dilma -, o governo do presidente Michel Temer apresentou em suas primeiras medidas a intenção de desconstruir tal processo e de retomar, com força total, os projetos neoliberais e conservadores na sociedade e, por consequência, na educação.

Com uma equipe de ministros constituídos apenas por homens brancos e ricos vem, numa velocidade surpreendente, impondo reformas nos vários setores sociais. Como primeira medida reduziu de 32 para 24 o número de ministérios por vias da extinção de algumas pastas e junção de outras. Tudo isso com a justificativa de que era necessário controlar os gastos do governo federal. A Medida Provisória (MP) no 726/2016, que foi aprovada no Senado em 08 de setembro de 2016 e virou a Lei $\mathrm{n}^{\mathrm{o}} 13.341$, de 2016, que reduzia as pastas a 23, mas após um protesto nacional foi desfeita a fusão do Ministério da Cultura com a pasta da Educação.

Entre a lista de ministérios e secretarias que foram extintas está a pasta que foi criada para garantir a promoção da igualdade, o Ministério das Mulheres, da Igualdade Racial e dos Direitos Humanos, ficando responsável por discutir esses temas referentes à antiga pasta o Ministério da Justiça e Cidadania, através da Secretaria das Mulheres, da Igualdade Racial e dos Direitos Humanos. O então ministério tem como ministro Alexandre de Morais, exsecretário de Segurança Pública de São Paulo, cujo currículo é de oposição, repressão e opressão aos movimentos sociais, a exemplo do movimento de ocupação das escolas pelos estudantes e do Movimento Passe Livre que sofreu represália do então ministro ex-secretário (TEIXEIRA, 2016).

Em carta contra a extinção dessa pasta, o Comitê Nacional de Educação em

Rafael Ferreira de Souza Honorato, Maria Zuleide da Costa Pereira 
Direitos Humanos (CNEDH) defendeu que:

as pautas de Direitos Humanos, das Mulheres, da Igualdade Racial e da Juventude, carregam consigo as marcas de lutas arduamente travadas ao longo de séculos para a conquista de direitos. Em âmbito nacional, os últimos anos foram decisivos para que essas agendas fossem reconhecidas como políticas públicas e ganhassem espaço próprio no Governo Federal.

Essas marcas não permitem retrocessos e devem garantir que esses direitos não se submetam novamente à invisibilidade. Ao ganharem status de Ministério, em 2003, os Direitos Humanos, as Políticas de Promoção da Igualdade Racial e as Políticas para as Mulheres foram reconhecidos como verdadeira política de Estado, para que não houvesse sobressaltos em momentos de alternância de partidos no poder. O que ocorre neste momento é a usurpação dessas conquistas (COMITÊ NACIONAL DE EDUCAÇÃO EM DIREITOS HUMANOS, 2016).

Não foi só o CNEDH que se posicionou; militantes dos movimentos étnicorraciais, feminista, Direitos Humanos, movimentos culturais e que defendem as diferenças e a promoção à igualdade se pronunciaram alegando que é uma volta ao marco zero, que todas as políticas de defesa e garantia dos direitos da mulher, dos negros, índios, etc., estão ameaçados. E, complementam, dizendo que tal medida foi contra os tratados internacionais de direitos humanos assinados nos últimos anos, entre eles: o Pacto Internacional dos Direitos Civis e Políticos; as Convenções da Tortura; da Discriminação Racional; dos Desaparecidos e da Violência Contra a Mulher. Vale ressaltar que, desde Fernando Henrique, o governo não excluiu a pasta de Direitos Humanos, durante o governo de FHC a Secretaria de Direitos Humanos também foi vinculada ao Ministério da Justiça (SALVADORI FILHO; MERLINO, 2016).

Ainda temos pastas como a Previdência Social, que perdeu o nome "Social" e foi dividida em dois órgãos: a Secretaria da Previdência acoplada ao Ministério da Fazenda, e o Instituto Nacional do Seguro Social (INSS) que foi vinculado ao Ministério do Desenvolvimento Social e Agrário. Tal fato é uma falácia às classes trabalhadoras e aos espaços de discussão democrática com os trabalhadores, empregadores, aposentados e o próprio governo. O que era para ser um dispositivo de beneficio social às classes populares, junto ao Ministério da Fazenda, tende a atender às expectativas econômicas, com cortes de gastos e redução dos benefícios em 30\%, como consta no texto da MP 739/2016.

Outra decisão que causou uma grande movimentação no país foi referente ao Ministério de Ciência, Tecnologia e Inovação que foi vinculado ao de Comunicação, gerando o Ministério de Ciência, Tecnologia, Inovações e Comunicação. Esse fato gerou uma mobilização, nas redes sociais e na plataforma Lattes, em âmbito nacional por parte de pesquisadores. A mobilização organizada pela Associação dos Docentes de UFRJ (ADUFRJ) decidiu, durante reunião da Sociedade Brasileira para o Progresso da Ciência 
(SBPC), trocar a foto do perfil do Lattes por uma imagem com a hashtag "FicaMCTI" (DANTAS, 2016; TUFFANI, 2016; PEDLOWSKI, 2016).

Pesquisadores $^{3}$ e instituições ${ }^{4}$ acadêmicas apontam que essa junção desvaloriza as pastas e minimiza a responsabilidade do Estado com a pesquisa; complementam que tal ação é uma forma de controlar a produção autônoma do conhecimento e que essa medida coloca o Brasil em uma posição marginal na produção de novas tecnologias. Para os pesquisadores, o que sobra são as incertezas, tendo em vista que o setor já convivia com cortes no segundo mandato da Presidenta Dilma (MATSUURA; FEREIRA, 2016).

Os cortes no orçamento não pararam por aí e o foco do novo governo foi nas políticas sociais voltadas às classes populares. Assim, anunciou uma redução de $30 \%$ dos gastos com a Educação e o Sistema Único de Saúde (SUS). Essa drástica redução alcançou os Estados, Município e o próprio Distrito Federal e vem gerando graves consequências no âmbito da saúde e escolarização das classes populares que vêm sendo excluídas do direito democrático à Educação.

Em meio a esse cenário, o governo Temer apresenta para votação na Câmara dos Deputados e no Senado a Proposta de Emenda Constitucional $n^{\circ}$ 241/2016 que após aprovada na Câmara foi registrada como PEC 55/2016 no Senado, com o intuito de limitar os gastos públicos para a educação e saúde, congelando esses gastos por 20 anos. Na educação, em 2017 serão investidos $18 \%$ dos impostos federais e entre 2018-2036 serão feitos reajustes pela inflação. Essa medida representa um retrocesso em todas as políticas educacionais que foram criadas até o momento. Se pensarmos no Plano Nacional de Educação (PNE), torna-se inviável a execução de todas as metas, com maior agravante para aquelas metas que exigem um crescimento no financiamento, a exemplo: a obrigatoriedade da educação das crianças e jovens de 4 a 17 anos, o estabelecimento do CAQ/CAQI, etc. Além de desarticular o espaço democrático de discussão, a exemplo do Fórum Nacional de Educação.

A onda neoliberal e conservadora adentrou o Ministério de Educação (MEC) seguida de inúmeras demissões e estreitamento dos espaços democráticos de discussão. $\mathrm{Na}$ Secretaria de Educação Continuada, Alfabetização, Diversidade e Inclusão (Secadi) e Secretaria Executiva foram exonerados 31 assessores, o que já afeta diretamente o funcionamento do Fórum Nacional de Educação (FNE) e o acompanhamento das ações do PNE. Em contrapartida, políticas de monitoramento e responsabilização vão tomando espaço no cenário nacional a exemplo da BNCC, cujo objetivo é tornar essa política o centro das políticas estatais para a educação nacional. Junto à base temos outros agravantes como a Escola Sem Partido e a 'Reforma' do Ensino Médio.

O que temos observado no cenário nacional é a investidura de uma bancada fundamentalista nas políticas educacionais, a qual vem apoiada por movimentos sociais como Escola Sem Partido e Unidos Pela Educação, além

3 Lista de pesquisadores que aderiram ao movimento \#Fica MCTI. Disponível em: $<$ http://ficamcti.redelivre.org.br/galeria/>. Acesso em 3 janeiro de 2016.

4 Entidades que apresentaram carta contra a fusão dos ministérios. Disponível em: $<$ http://www.sindct.org.br/index.php?q=node/3662>. Acesso em 3 janeiro de 2016. 
de empresários que tendem a fortalecer a relação público/privado para fazerem do Estado uma fonte de capital, que Freitas chama de reformadores empresariais da educação (FREITAS, 2012). Esses movimentos ao redor de tais políticas geraram discussões sobre o viés ideológico da escola, a exemplo do Marxismo, Ideologia de Gênero, sexualidade,etc., na ideia de conseguir colocar como crime o "assédio ideológico".

É nesse sentido que Quinalha (2016), ao elencar as três facetas do impeachment, defende que a faceta:

[...] mais subterrânea e de alcance ainda imprevisível, talvez seja a mais perversa por sua invisibilidade e por afetar segmentos sociais desamparados de um estatuto legal de proteção em nossa democracia: trata-se da agenda moral desse golpe tramado e executado por homens brancos, heterossexuais e cisgênero (QUINALHA, 2016, p. 134).

Assim, nesse novo governo as pautas dos direitos humanos chegam até a Presidência pelas portas dos fundos e são mantidas em observação constante por:

uma moral sexual retrógrada, centrada em um modelo único de família como célula elementar da sociedade, [...] prestigiando apenas o matrimônio exclusivo entre pessoas do sexo oposto e com papéis de gênero complementares, cabendo às mulheres serem 'belas, recatadas e do lar' (QUINALHA, 2016, p. 137).

Uma vez compreendida a conjuntura nacional, onde as demandas sociais das classes populares e os processos de inclusão em busca de uma equidade estão em risco, no próximo tópico focaremos nas políticas educacionais do estado da Paraíba, principalmente as com foco na EJA, tentando perceber as (des)continuidades referentes à conjuntura conservadora, fundamentalista e neoliberal da conjuntura nacional.

\section{Disputas em torno da Significação do Gênero e sua Inserção nas Políticas Educacionais Paraibanas}

Nesta sessão, coloca-se para análise o Plano Estadual de Educação da Paraíba (2015-2025) e as Portarias 513/2011, 423/2012, 1.115/2014, 679/2015 e 1.050/2016, todas correspondentes às Diretrizes Operacionais para o Funcionamento das Escolas da Rede Estadual de Ensino nos anos de 2012, 2013, 2014, 2015, 2016 e 2017, respectivamente. Os documentos a serem analisados foram extraídos do site da Secretara do Estado de Educação da Paraíba.

Partir dos estudos de Bowe, Ball e Gold (1992); Ball (1989, 1994) e Ball, Maguire e Braun (2016), direciona a nossa preocupação para a representação ou exclusão do gênero no processo político como interesse de lutas dos grupos dos movimentos sociais dentro das arenas dos contextos do ciclo de políticas. Partimos de indagações como: as questões de gênero são contempladas em quais políticas educacionais paraibanas? Como essas discussões chegam às 
políticas curriculares para a EJA? No processo de gestão dessas políticas, quais foram os sujeitos envolvidos e ouvidos? Como foram ouvidos? Isso é necessário para que possamos perceber que "intenções" estão por trás dos textos políticos e como esses textos se aproximam ou se distanciam das decisões nacionais que excluíram o gênero das metas do PNE (2014-2024).

Dias e Chaves (2015) já apresentaram em seus estudos a exclusão das questões de gênero e sexualidade do PNE (2014-2024), ressaltando que a sociedade civil é organizada; através do documento final da Conferência Nacional de Educação (CONAE), em 2014, defendia a necessidade de discussão nas escolas através da transversalização desse tema nos diversos conteúdos e componentes curriculares, bem como na formação inicial e continuada dos profissionais da educação. Todavia, no processo de votação do plano, tais incumbências foram suprimidas.

Depois de sancionado pela Presidenta Dilma Rousseff, em 25 de junho de 2014, os Estados e Municípios tinham até 26 de junho de 2016 para construírem seus planos. Isso fez com que os movimentos tanto em defesa quanto contra as discussões de gênero e sexualidade se intensificassem. A bancada evangélica, responsável pela exclusão dos temas no PNE, defendia que a 'Ideologia de Gênero' deturparia a família tradicional, distorcendo o conceito do que é ser homem e ser mulher. Estamos falando aqui na esfera do contexto de influência, ou seja, os discursos ideológicos permeando a produção de textos da política.

O que chamou a nossa atenção é que a maioria dos estados conseguiu garantir esses dois pontos em seus planos, entre eles a Paraíba, como mostra a figura 1. Destaca-se que, na região Nordeste, apenas quatro estados garantiram a inserção da temática em suas metas: Alagoas, Paraíba, Rio Grande do Norte e Maranhão. Entretanto, no caso de Alagoas no mesmo ano os deputados estaduais derrubaram o veto do governador Renam Filho (PMDB) e aprovaram o Projeto Escola Livre, que visa manter 'neutralidade' em sala de aula e os professores estão impedidos de 'doutrinar' e 'induzir' alunos em assuntos políticos, religiosos e ideológicos, sob pena até de demissão.

Segundo dados do Instituto de Pesquisas Econômicas Aplicadas (IPEA) (2013), a Paraíba ocupa o oitavo lugar no ranking dos estados com maior incidência de morte e violência contra a mulher; o índice do estado é maior que o nacional. Então, podemos indagar: como um estado tão machista conseguiu incorporar no seu plano as questões de gênero e sexualidade? Quais as metas e estratégias que foram construídas para atender às especificidades dessa questão?

O Documento do PEE (2015-2025) tem 204 páginas; a primeira menção à palavra gênero é feita no item 1.7 sobre a Educação de Jovens e Adultos e é referente a dados estatísticos; volta a aparecer no item 1.10, o qual trata da Educação em Direitos Humanos. Neste, o gênero assume um espaço de discussão referente à identidade de gênero, mas não são especificadas estratégias plausíveis e utilizáveis para esse tema. Mas, foi na meta 13, que compreende a implementação da Educação em Direitos Humanos, que as questões das diferenças foram incorporadas com exceção da Educação Étnicorracial, Indígena, Quilombola e Cigana que, por serem modalidades de ensino, foram contempladas nas metas $14,15,16$ e 17, respectivamente. 
Figura 1 - Estados que incluíram menções à igualdade de gênero no PEE.

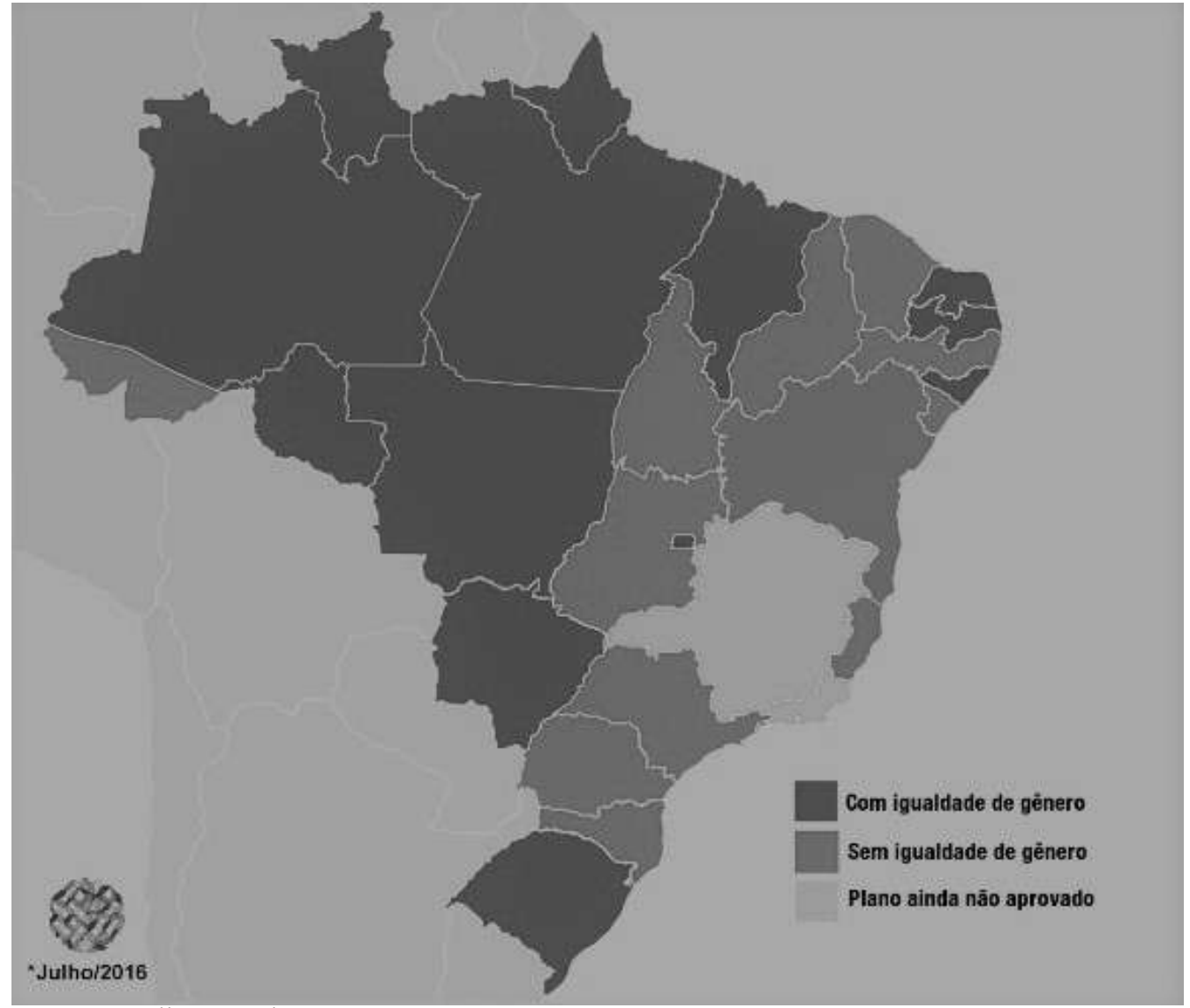

Fonte: De olho nos planos, 2017.

A meta 13 possui 5 estratégias, são elas:

13.1. Garantir a inclusão de práticas pedagógicas na educação que contemplem a educação em direitos humanos no sentido da convivência e respeito entre os diferentes, a mediação de conflitos e a educação para a paz;

13.2. Apoiar, técnica e ou financeiramente, a elaboração de materiais didático-pedagógicos para educação em direitos humanos e diversidade sociocultural;

13.3. Monitorar o encaminhamento dos casos notificados de violência e discriminação da/na escola articulando a rede de proteção social;

13.4. Promover a inserção da educação em direitos humanos, conforme as diretrizes nacionais nos processos de formação inicial e continuada dos trabalhadores da educação nas redes de ensino, no sistema prisional e nos estabelecimentos de medidas socioeducativas;

13.5. Estimular os estudos de educação em direitos humanos e de diversidade, na formação inicial e continuada dos profissionais da educação, nas atividades de ensino, pesquisa e extensão, de forma interdisciplinar, transdisciplinar e transversal, articulando-os à promoção dos direitos humanos (meta do Plano Nacional de

Rafael Ferreira de Souza Honorato, Maria Zuleide da Costa Pereira 
Educação em Direitos Humanos) (PARAÍBA, 2015, p. 81).

Apesar de no texto introdutório para a construção dessa meta, que visa implementar a educação em direitos humanos em todos os níveis, etapas e modalidades de ensino na Paraíba, a questão sobre identidade de gênero aparecer em citações e no decorrer do texto a palavra gênero ser colocada várias vezes, esse tema não ganha nenhuma notoriedade, então como garantir que o tema será um dos focos do atual plano?

Estudos como os de Pereira (2015), Carvalho et al. (2016), Gomes (2008) e Connell e Pearse (2015) trazem à discussão a ideia de que existe uma tendência a naturalizar a omissão do termo 'gênero' das políticas, bem como trocar esse termo por outros que geram uma multiplicidade de sentidos, o que acaba levando os sujeitos a, mais uma vez, afastarem-se da discussão de gênero.

Nos escritos de Ball (1994), ele explica bem essa ocorrência quando pensa o contexto das estratégias políticas, pois é nessa arena que os discursos ideológicos buscam estratégias para que as questões que não são dos seus interesses não apareçam ou fiquem, de certa forma, escondidas nas entrelinhas. Bowe, Ball e Gold (1992) vão complementar esse pensamento ressaltando que quando o texto das políticas for carregado de (im)possibilidades, limitações, contradições e gerado em certo espaço/tempo, quando chega na prática necessita do empenho dos atores da escola.

Ball (1989) já destacava que tal empenho, por sua vez, é ligado às relações de poder, jogos de interesses, singularidades pessoais, culturais, religiosas, etc. Voltamos a Ball (1994) para refletir que, no contexto dos efeitos, o que teríamos era a opção por não trabalhar temas como: gênero, sexualidade, religiosidade, entre outros, que são inapropriados às vistas do conservadorismo.

Para além do PEE, existem as Diretrizes Operacionais para o Funcionamento das Escolas da Rede Estadual de Ensino que são publicadas anualmente e:

apresentam os aspectos normativos que regem as ações das escolas e as orientações que tratam da sua organização estrutural e funcional, além da descrição e operacionalização dos principais programas e projetos da Secretaria de Estado da Educação e do Ministério da Educação (PARAÍBA, 2016, p. 6).

Desde 2012 que as diretrizes orientam os processos educacionais na rede para 2013, fazendo menção à necessidade de pensar tais questões de gênero na escola. As diretrizes que foram utilizadas em 2013 já traziam em seu texto, de forma restrita, a Educação do Campo, em que é fundamental reconhecer "a diversidade do campo em todos os seus aspectos: sociais, culturais, políticos, econômicos, de gênero, geração e etnia contemplada nas propostas pedagógicas (Art. 5)" (PARAÍBA, 2012, p. 20). Tal menção corresponde ao que defende a Resolução $n^{\circ} 1$, de 03 de abril de 2002, que institui as Diretrizes Operacionais para a Educação Básica nas Escolas do Campo.

Nesse mesmo documento foi criado um tópico só para a questão da 
transversalidade que elenca temas como: educação da diversidade étnicorracial, educação quilombola, Programa Nacional de Educação Fiscal (PNAF), educação para o consumo, educação em direitos humanos e educação ambiental. As questões de gênero e sexualidade poderiam vir vinculadas à Educação em Direitos Humanos; todavia, o texto não faz nenhuma colocação sobre a necessidade de tais questões serem pontuadas nos currículos escolares, o que deixou o tema à margem.

Nas diretrizes operacionais que se seguiram criou-se um tópico para a organização curricular das escolas onde orientam para que nas revisões dos Projetos Político-Pedagógicos sejam inseridas questões sobre:

[...] valorização e promoção dos Direitos Humanos, mediante temas relativos a gênero, identidade de gênero, raça e etnia, religião, orientação sexual, pessoas com deficiência, entre outros, bem como práticas que contribuam para a igualdade e para o enfrentamento de todas as formas de preconceito, discriminação e violência sob todas as formas; [...] (PARAÍBA, 2013, p. 29).

Houve uma ruptura desse processo no ano de 2016, cuja portaria foi de $\mathrm{n}^{\mathrm{o}}$ 679, de 12 de novembro de 2015, com redação que se assemelhou à da portaria de 2012, a qual instituiu diretrizes para 2013 e tratou de indagar as questões de gênero apenas na Educação do Campo. Todavia, para nossa surpresa e com as limitações do PEE (2015-2025), as diretrizes para 2017, que não saíram como portaria, além de fazer as indagações para a construção dos PPPs, trazem nas matrizes curriculares cargas horárias específicas para o trabalho com temas de gênero, sexualidade e questões étnicorraciais, fazendo esse mesmo apontamento para a EJA, para isso, tendo que reduzir a carga horária dos componentes de Português e Matemática.

$\mathrm{O}$ texto apresenta que para as regras de funcionamento da EJA:

Ao longo do ano, serão desenvolvidas atividades de quatro Projetos Complementares (PC) ao currículo: Incentivo à Leitura, Trânsito, Gênero e um de temática comunitária, selecionada com os alunos. Os projetos serão desenvolvidos considerando todas as áreas de conhecimentos, sendo que cada área será responsável pela coordenação de um dos Projetos (PARAÍBA, 2016, p. 57).

Percebemos, nessas linhas que escrevemos sobre essas duas políticas do estado da Paraíba, avanços e recuos constantes no que concerne à discussão do gênero e sua corporificação no currículo da educação básica, principalmente no da EJA que só vem a ficar nítido agora em 2017. Gomes (2008, p. 25) nos ajuda a refletir sobre isso quando diz que para compreender esse processo é necessário estar atento às causas "[...] políticas, econômicas e sociais. De fenômenos como etnocentrismo, racismo, sexismo, homofobia e xenofobia $[\ldots] "$.

Para Connell e Pearse (2015, p. 25), falar sobre gênero é um assunto permeado por muitos "preconceitos, mitos e franca falsidade". A exemplo do 
PEE (2015-2025), que traz na gramática do texto o artigo feminino e masculino antes do sujeito, mas, que ao tratar as questões de gênero com mais profundidade, ficou mais tímido e vinculou a Educação para a equidade dos gêneros à Educação em Direitos Humanos. Para as autoras supracitadas (CONNELL; PEARSE, 2015, p. 45), “[...] a língua importa, mas não fornece um arcabouço consistente para compreender o gênero [...]". Elas citam países como China, Alemanha, entre outros, onde não há distinção de gênero na língua, mas a cultura acaba por criar outros dispositivos, que são bem mais agravantes, para definir as desigualdades entre os gêneros. Ou seja, a linguagem não sexista é positiva, mas não imprime ações que vão mudar a cultura e a diferença entre os gêneros numa sociedade patriarcal como a nossa.

Acreditamos que o que necessitamos é de uma efetiva tomada de decisão, como ressaltam Carvalho et al. (2016, p. 49), ao afirmar que o que precisamos é de "[...] novas relações e práticas sociais; [que impliquem em] mudança cultural, o que não se dá sem a reeducação das gerações adultas (educação ao longo da vida) concomitante à educação das novas gerações".

E como nos alertam Ball (1989, 1994); Ball, Maguire e Braun (2016) e Bowe, Ball e Gold (1992), a gestão de políticas precisa se aproximar cada vez mais da escola e dos profissionais que fazem sua atuação, com o objetivo de tentar construir propostas em que os antagonismos sejam capazes de negociar espaços, criando possibilidades para favorecimento da equidade entre as diferenças. Só assim, envolvidos inteiramente nos processos democráticos de formulação de políticas, é que eles irão se sentir representados e apoiarão as proposições que eles mesmos ajudaram a construir.

\section{Algumas Considerações}

Observar a trajetória das políticas analisadas, através dos referenciais epistemológicos escolhidos por nós, nos levou a compreender alguns aspectos da política do currículo e do gênero, bem como nos deixaram algumas outras questões que precisam de um tempo maior para ser analisadas, pois exigem uma maior reflexão e, até mesmo, a busca de outras fontes. $O$ que não podemos deixar de ressaltar é a complexidade do processo de gestão de uma política educacional, tendo em vista as relações de poder e as várias frentes que existem em torno das políticas em busca de serem representadas, e assim chegamos ao caráter híbrido de uma política da educação. O texto que emerge dos tensionamentos ideológicos não é representativo de uma única ideologia que estava em disputa no processo de formulação do texto.

Ao mesmo tempo, o texto vira um latifúndio político, onde quem conseguiu uma adesão maior de participantes no momento da negociação leva a maior fatia, ou seja, consegue um espaço maior de representação para seus interesses. Todavia, outra questão é que essa disputa acontece em diferentes contextos e os resultados desses conflitos, mesmo que aconteçam em espaços diferentes em tempos iguais, podem ser diferentes, pois cada contexto pode ter uma aglomeração de interesses diferentes. Assim, pode ser que num cenário nacional, as questões de gênero fiquem à margem dos interesses, mas, em seus contextos macro ou micro, podem acabar ganhando força e espaço de representação nas políticas locais. A relação entre o macro, meso e micro não 
obedece a uma hierarquia tão fixa como se imagina.

É partindo de tal percepção que estamos começando a compreender que os reais efeitos das políticas no que tange à oferta de serviços, direitos em todos os âmbitos não são assegurados pelos textos das políticas. Entendemos que esses direitos são consequências de disputas e conflitos que forçam as agências governamentais a incluir certas demandas populares na agenda e são capazes de mudar as regras do jogo no processo. Sendo assim, as políticas estatais, governamentais, ou quaisquer outras medidas que possam ser feitas através da produção de texto, não são capazes de garantir condições concretas de acesso aos direitos instituídos nas políticas. Parece-nos que o direito é contingente e o acesso a eles também, ou seja, tem que haver formas de movimentos contrahegemônicos.

Quanto ao gênero, esse também está dentro de um processo contínuo onde as relações de gênero são reinventadas. Esse conjunto de relações sociais está, também, dentro de tensões diferentes, com níveis e graus de representações também diferentes. Sendo assim, entendemos que a mulher, dependendo do contexto, vai ocupar espaços diversos em relações sociais, políticas e culturais, mas com fortes tendências à desvalorização ou vinculação do seu papel social às formas subalternas e subordinadas às funções masculinas. A educação, nesse caso, é o meio por onde esses estigmas são mantidos e assegurados; por isso, em tempo de mudança a educação sempre é uma das primeiras pautas.

Sobre a Educação de Jovens e Adultos, este ainda é um espaço que passa despercebido, onde as diferenças estão sendo constantemente reduzidas à geracionalidade, o que dificulta a gestão de políticas que busquem dar visibilidade a problemas mais recorrentes de permanência desses jovens e adultos no espaço de formação, como, também, a uma formação mais humanista e crítica do cidadão para que este entenda quais seus direitos e deveres para com a sociedade.

As políticas do currículo têm sido foco atual das ideologias conservadoras, as quais querem fortalecer o cabresto, a regulação das práticas pedagógicas que pode colocar a escola, os docentes e, por consequência, a sociedade dentro dos padrões que eles entendem como certos. No atual contexto educacional, o Brasil vive um momento de fortes tensões entre a significação de currículo mínimo, BNCC e os currículos praticados, ou seja, os currículos que as escolas constroem em seus contextos. Para ganhar força nesse movimento de construção de um currículo enciclopédico, tecnicista, machista, branco, heterossexual, cristão, etc., outras políticas conservadoras vêm pressionando o currículo escolar a assumir um padrão único de cultura, cerceando o papel da escola e dos docentes no que concerne à autonomia de (re) criar os processos formativos.

Por fim, a Paraíba vem na contramão de uma política conservadora, buscando garantir a pluralidade nas discussões políticas educacionais e na gestão de seus currículos, como foi elencado nos tópicos acima. Mas, essas relações entre os movimentos de esquerda precisam ser mais bem articuladas; além disso, é preciso que continuemos firmes na produção de sentidos das várias políticas e seus desdobramentos, precisamos exercer influência através dos mecanismos acadêmicos, populares, sociais, políticos, etc. Para isso, continuemos contestantes, construindo propostas e respostas, enfrentando as 
contradições e buscando sermos representados nas políticas.

\section{Referências}

APPLE, M. W. Podem as pedagogias críticas sustar as políticas de direita? Cadernos de Pesquisa, n. 16, p. 107 - 142, 2002.

AVELAR, M. Entrevista com Stephen J. Ball: Uma Análise de sua Contribuição para a Pesquisa em Política Educacional. Archivos Analíticos de Políticas Educativas, Arizona, v. 24, n. 24, p. 1 - 18, 2016.

BALL, S. J. Edication Reform: a critical an post-structural approach. Philadelphia: Open University Press, 1994.

BALL, S. J. La micropolítica de la escuela. Hacia una teoría de la organización escolar. Tradução de Néstor Míguez. Madrid: Paidos, 1989.

BALL, S. J.; MAGUIRE, M.; BRAUN, A. Como as escolas fazem as políticas: atuação em escolas secundárias. Tradução de Bridon Janete. Ponta Grossa: Editora UEPG, 2016.

BOWE, R.; BALL, S. J.; GOLD, A. Reforming Education and Changing Schools: Case Studies in Policy Sociology. London: Routledge, 1992.

BRASIL. Lei No 13.341, de 29 de setembro de 2016. Brasília: Presidência da República, Casa Civil, Subchefia para Assuntos Jurídicos, 2016a. Disponível em <http://www.planalto.gov.br/CCIVIL_03/Ato20152018/2016/Lei/L13341.htm>. Acesso em 2 de janeiro de 2017.

BRASIL. Medida Provisória No 726. Diário Oficial da União, Brasília, 12 de maio de 2016b. Disponível em $<\mathrm{http}$ :/pesquisa.in.gov.br/imprensa/jsp/visualiza/index.jsp?data $=$ 12/05/2016\&jornal=1000\&pagina $=3 \&$ totalArquivos $=10>$. Acesso em 2 de janeiro de 2017.

BRASIL. Medida Provisória No 739, de 07 de julho de 2016. Brasília: Presidência da República, Casa Civil, Subchefia para Assuntos Jurídicos, 2016c. Disponível em <http://www.planalto.gov.br/ccivil_03/_ato20152018/2016/Mpv/mpv739.htm>. Acesso em 2 de janeiro de 2017.

BRASIL. Resolução $\mathbf{N}^{\mathbf{0}}$ 1, de 3 de abril de 2002, que institui diretrizes operacionais para a educação básica nas escolas do campo. Brasília: Ministério da Educção, Conselho Nacional de Educação, Secretaria de Educação Básica, $2002 . \quad$ Disponível em $<$ http://portal.mec.gov.br/index.php?option=com_docman\&view=download\&a lias=13800-rceb001-02-pdf\&Itemid=30192>. Acesso em 2 de janeiro de 2017.

CARVALHO, M. E. P. D. et al. Direitos humanos das mulheres e das pessoas LGBTQI: inclusão da perspectiva da diversidade sexual e de gênero 
nas educação e na formação docente. João Pessoa: Editora da UFPB, 2016.

CHAUI, M. A nova classe trabalhadora brasileira e a ascensão do conservadorismo. In: JINKINGS, I.; DORIA, K.; CLETO, M. Por que gritamos golpe? para entender o impeachment e a crise. São Paulo: Biotempo, 2016, p. $15-22$.

COMITÊ NACIONAL DE EDUCAÇÃO EM DIREITOS HUMANOS. Manifesto pela Democracia - CNEDH. União Nacional dos Dirigentes Municipais de Educação, 2016. Disponível em $<$ https://undime.org.br/portal/documento/arquivo/1392>. Acesso em 2 de janeiro de 2017.

CONNELL, R.; PEARSE, R. Gênero: uma perspectiva global. Tradução de Marília Moschkovich. 3. ed. São Paulo: nVersos, 2015.

COSTA, G. O desmonte do Estado. In: JINKINGS, I.; DORIA, K.; CLETO, M. Por que gritamos golpe? para entender o impeachment e a crise. São Paulo: Boitempo, 2016, p. 9 - 10.

DANTAS, C. Pesquisadores protestam na web por volta de Ministério da Ciência. G1, 2016. Disponível em <http:/g1.globo.com/ciencia-esaude/noticia/2016/06/pesquisadores-protestam-na-web-por-volta-deministerio-da-ciencia.html>. Acesso em 3 de janeiro de 2017.

DIAS, A. F.; CHAVES, G. N. Experiências de transversalização de gênero no ensino superior. In: PEREIRA, M. Z. D. C.; ALBINO, Â. C. A.; DANTAS, V. $X$. Políticas de currículo e formação: desafios contemporâneos. João Pessoa: Editora da UFPB, 2015, p. 169 - 174.

FOUCAULT, M. The history of sexuality. harmondsworth: Penguin, 1981.

FREITAS, L. C. D. Os reformadores empresariais da educação: da desmoralização do magistério à destruição do sistema público de educação. Educação e Sociedade, v. 33, n. 119, p. 379 - 404, 2012.

GOMES, N. L. Diversidade e currículo. In: BEAUCHAMP, J.; PAGEL, S. D.; NASCIMENTO, A. R. Indagações sobre currículo. Brasília: Ministério da Educação, Secretaria de Educação Básica, 2008, p. 5 - 47.

HAWKES, T. Structuralism and Semiotics. London: Methuen, 1977.

IPEA - Instituto de Pesquisas Econômicas Aplicadas. 2013. Violência contra a mulher: feminicídios no Brasil. Brasília: IPEA. 5 páginas. Disponível em $<$ http://www.ipea.gov.br/portal/images/stories/PDFs/130925_sum_estudo_femi nicidio_leilagarcia.pdf. Acesso em 18 de março de 2015.

MATSUURA, S.; FEREIRA, P. Pesquisadores criticam fusão de ministérios da Ciência e Comunicações. O Globo, 2016. Disponível em $<$ http://oglobo.globo.com/sociedade/ciencia/ pesquisadores-criticam-fusao-de- 
ministerios-da-ciencia-comunicacoes-19318187>. Acesso em 3 de janeiro de 2017.

OLIVEIRA, R. P. Reformas educativas no Brasil na década de 90. In: OLIVEIRA, R. L. P.; CATANI, A. M. (Org.). Reformas educacionais em Portugal e no Brasil. Belo Horizonte: Autêntica, 2000, p. 77 - 94.

PARAÍBA. Diretrizes Operacionais para o Funcionamento das Escolas da Rede Estadual de Ensino para 2017. João Pessoa, Secretaria de Estado da Educação, 2016.2 Disponível em $<$ http://paraiba.pb.gov.br/downloads/Diretrizes_Operacionais_2017.pdf>. Acesso em 1 de janeiro de 2017.

PARAÍBA. Lei $\mathbf{N}^{\mathbf{o}} \mathbf{1 0 . 4 8 8}$, de 23 de junho de 2015, que institui o Plano Estadual de Educação da Paraíba. João Pessoa: Secretaria de Estado da Educação, 2015. Disponível em <http://static.paraiba.pb.gov.br/2016/07/Lein $\%$ C2\%BA-10.488-Plano-Estadual-de-Educa\%C3\%A7\%C3\%A3o-ANEXODO-PLANO-ESTADUAL-1-3-1.pdf $>$. Acesso em 1 de janeiro de 2017.

PARAÍBA. Portaria $\mathbf{N}^{\mathbf{0}} \mathbf{4 2 3}$, de 13 de novembro de 2012. João Pessoa: Secretaria do Estado de Educação, 2012. Disponível em $<$ http://static.paraiba.pb.gov.br/2012/12/Diretrizes-Operacionais-de-Ensino2013-paginado-na-grafica.pdf $>$. Acesso em 2 de janeiro de 2017.

PARAÍBA. Portaria No 546, de 19 de novembro de 2013, que institui normas para a gestão de pessoal e adota outras providências. João Pessoa: Secretaria de Estado da Educação, 2013. Disponível em $<$ http://static.paraiba.pb.gov.br/2013/12/Diretrizes-Operacionais-para-oFuncionamento-das-Escolas-da-Rede-Estadual-de-Ensino-no-ano-2014.pdf $>$. Acesso em 1 de janeiro de 2017.

PARAÍBA. Portaria $\mathbf{N}^{\mathbf{0}} \mathbf{1 . 1 1 5}$, de 20 de novembro de 2014, baixa instruções complementares para gestão de pessoal relativas ao ano letivo 2015 e dá outras providências. João Pessoa: Secretaria de Estado da Educação, 2014. Disponível em $\quad<$ http://static.paraiba.pb.gov.br/2013/12/DiretrizesOperacionais-SEE-PB-2015.pdf $>$. Acesso em 1 de janeiro de 2017.

PEDLOWSKI, M. A extinção do MCTI e suas implicações para o desenvolvimento nacional. Blog do Pedlowski, 2016. Disponível em $<$ https://blogdopedlowski.com/2016/05/13/a-extincao-do-mcti-e-suasimplicacoes-para-o-desenvolvimento-nacional/>. Acesso em 3 de janeiro de 2017.

PEREIRA, M. Z. D. C. Construção das relações de gênero no campo das telecomunicações. João Pessoa: Editora da UFPB, 2015.

PEREIRA, M. Z. D. C. Currículo, discurso e discursos. In: MACEDO, E.; SIDNEI, M. R.; AMORIM, A. C. Discurso, texto, narrativa nas pesquisas em currículo. Campinas: FE/UNICAMP, 2009, p. 114 - 123. 
QUINALHA, R. "Em nome de Deus e da família": um golpe contra a diversidade. In: JINKINGS, I.; DORIA, K.; CLETO, M. Por que gritamos golpe? para entender o impeachmen e a crise. São Paulo: Boitempo, 2016, p. $131-138$.

ROCHA, N. F. E. Base nacional comum curricular e micropolítica: analisando os fios condutores. 2016. Dissertação (Mestrado em Educação) Programa de Pós-Graduação em Educação da Universidade Federal da Paraíba, João Pessoa.

RURY, J.; MIREL, J. The political economy of urban education. In: APPLE, M. W. (Ed.). Review of research in education. Washington: American Educational Research Association, 1997, v. 22, p. 49 - 110.

SADER, E. A construção da hegemonia pós-neoliberal. In: SADER, E. 10 anos de governos pós-neoliberal no Brasil. Rio de Janeiro: FLACSO, 2013, p. $135-144$.

SALVADORI FILHO, F.; MERLINO, T. Um governo sem mulheres, sem direitos e sem igualdade racial. Carta Capital, 2016. Disponível em $<\mathrm{http}$ ://ponte.cartacapital.com.br/um-governo-sem-mulheres-sem-direitos-esem-igualdade-racial/> . Acesso em 1 de janeiro de 2017.

SCOTT, J. W. Gênero: uma categoria útil de análise histórica. Educação \& Realidade, Porto Alegre, v. 20, n. 2, p. 71 - 99, 1995.

SELDEN, S. Inheriting shame. New York: Teachers College Press, 1999.

TEITELBAUM, K. Schooling for good rebels. New York: Teachers College Press, 1996.

TEIXEIRA, B. População ocupa a ocupação e enxota MBL de escola em Curitiba. Rede Brasil Atual, 2016. Disponível em $<$ http://www.redebrasilatual.com.br/blogs/blog-na-rede/2016/10/populacaoocupa-a-ocupacao-e-enxota-mbl-de-escola-em-curitiba-9688.html>. Acesso em 2 de janeiro de 2017.

TUFFANI, M. Temer, Kassab e o Ministério da Ciência, Tecnologia, Inovações e Comunicações. Direto da ciência: análise, opinião e jornalismo investigativo, 2016. Disponível em $<$ http://www.diretodaciencia.com/2016/05/13/temer-kassab-e-o-mctic/>. Acesso em 3 de janeiro de 2017. 